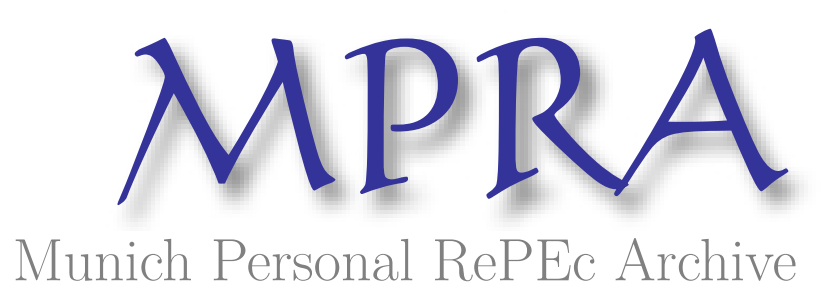

\title{
Capacity choice in an international mixed triopoly
}

Ohnishi, Kazuhiro

21 May 2019

Online at https://mpra.ub.uni-muenchen.de/94051/

MPRA Paper No. 94051, posted 21 May 2019 08:50 UTC 


\title{
Capacity choice in an international mixed triopoly
}

\author{
Kazuhiro Ohnishi* \\ Institute for Basic Economic Science, Japan
}

\begin{abstract}
This paper considers a mixed triopoly model where a state-owned firm, a domestic labor-managed firm and a foreign capitalist firm are allowed to pre-install capacity as a strategic commitment device. First, each firm simultaneously and independently chooses its capacity level. None of the firms can reduce or dispose of capacity. Second, each firm simultaneously and independently chooses its output level. The paper shows that there is an equilibrium solution where only the domestic labor-managed firm pre-installs excess capacity as a strategic commitment device.
\end{abstract}

Keywords: Excess capacity; State-owned firm; Domestic labor-managed firm; Foreign capitalist firm

JEL classification: C72; D21; F23; L30

*Email: ohnishi@e.people.or.jp 


\section{Introduction}

Many researchers have studied the possibility of firms using excess capacity as a strategic commitment device in oligopolistic competition. For instance, Dixit (1980) considers a two-stage game model between an incumbent and a potential entrant, and shows that the incumbent installing excess capacity in the first stage is able to deter the potential entrant in the second stage. Ware (1984) considers three-stage Cournot competition in which an incumbent installs capacity in the first stage, an entrant installs capacity in the second stage, and a quantity equilibrium is established in the third stage. He demonstrates that although his three-stage equilibrium is qualitatively similar to Dixit's two-stage equilibrium, it differs in that the strategic advantage available to the first mover is lessened. In addition, Poddar (2003) examines a two-stage game model of strategic entry deterrence under demand uncertainty, and shows that to improve its strategic position in the product market competition an incumbent will choose a level of capacity that may remain idle in a low state of demand. There is also a great deal of literature (see, for example, Wenders, 1971; Spence, 1977; Eaton and Lipsey, 1981; Basu and Singh, 1990; Bulow, Geanakoplos and Klemperer, 1985a; Bagwell and Ramey, 1996; Kim, 1996; Ohnishi, 2000; Grenadier, 2002; Novy-Marx, 2007; Aguerrevere, 2009). All theseresearches focus on the behaviors of profit-maximizing firms.

The first theoretical study of a state-owned public firm was done by Merrill and Schneider (1966), and since then, the theoretical contributions of mixed oligopoly markets including state-owned public firms have been made by many researchers all over the world. For instance, Nett(1994)examines a mixed duopoly market where a state-owned fim coexists with a capitalist firm, and proves that the 
capitalist firm produces at a lower variable cost compared to the state-owned firm. He also shows that the capitalist firm sells a greater amount of output than the state-owned firm. Poyago-Theotoky (1998) considers a mixed R\&D duopoly where a state-owned firm and a capitalist firm compete to introduce a new product or process under uncertainty and easy imitation, and shows that the capitalist firm invests less in R\&D than the state-owned firm. There are also many other related research works (see, for example, Cremer, Marchand and Thisse, 1991; Willner, 1994; Fjell and Pal, 1996; George and La Manna, 1996; Poyago-Theotoky, 2001; Fjell and Heywood, 2002; Beladi and Chao, 2006; Chao and Yu, 2006; Bárcena-Ruiz, 2007; Barcena-Ruiz and Garzón, 2007; Lu, 2007; Saha and Sensarma, 2008; Art, Heywood and MoGinty, 2009; Lu and Poddar, 2009; Roy chowdhury, 2009; Wang and Wang, 2009; Heywood and Ye, 2010; Zhang and Li, 2013; Pal and Saha, 2014; Hsu, Lee and Wang, 2018). All these researches examine mixed oligopoly markets in which state-owned public firms compete with capitalist firms.

The pioneering work on a theoretical model of a labor-managed firm is conducted by Ward (1958), and since then, the analysis of mixed oligopoly models with labor-managed and capitalist firms has been also frequently encountered in the literature on economic theory. For instance, Stewart (1991) explores strategic entry interactions between capitalist and labor-managed firms using a framework suggested by Dixit (1980), and shows that a potential labor-managed entrant is more likely to be accommodated into the industry than a potential capitalist entrant. He considers duopoly competition in which a capitalist or labor-managed incumbent unilaterally chooses a pre-entry capacity level to deter entry by a capitalist or labor-managed firm and addresses the issue 
of noncooperative entry deterrence. Cremer and Crémer (1992) consider duopolistic competition where the firms decide both the employment level and the capital stock simultaneously, and show that the labor-managed firm produces less output than the capitalist firm in a two-stage Cournot duopoly regime. Neary and Ulph (1997) study the relative profitability of labor-managed and capitalist firms in a mixed duopoly equilibrium with strategic investment, and show that no equilibrium can have both firms making zero profit. Lambertini and Rossini (1998) investigate the behaviors of labor-managed and capitalist firms in a two-stage Cournot duopoly model with capital strategic interaction, and demonstrate that the capitalist firm always under-invests while the labor-managed firm always over-invests. In addition, Ohnishi (2008) clarifies the behaviors of a labor-managed firm and a capitalist firm in a quantity-setting model with a strategic commitment, and shows that the introduction of capacity investment into the analysis of the mixed duopoly model may be effective for the labor-managed firm. There are also a great number of papers (for example, see Law and Stewart, 1983; Horowitz, 1991; Stewart, 1992; Askildsen and Ireland, 1993; Ireland and Stewart, 1995; Okamura and Futagami, 1998; Lambertini, 2001; Ireland, 2003; Cuccia and Cellini, 2009; Luo, 2013; Delbono and Lambertini, 2017). All these researches investigate mixed oligopoly markets where labor-managed firms compete against capitalist firms.

Only a few papers have been published on the study of mixed oligopoly models with state-owned and labor-managed firms. For example, Delbono and Rossini (1992) investigate a mixed duopoly formed by a state-owned firm and a labor-managed firm in a Cournot-Nash setting, and show that there is a unique locally stable equilibrium in which the state-owned firm produces 
more than the labor-managed firm produces.

We consider a mixed triopoly model in which there are a state-owned firm, a labor-managed firm and a capitalist firm. Ohnishi (2018) examines a market comprising a labor-managed firm, a capitalist firm and a state-owned firm, and demonstrates that there is a subgame perfect equilibrium in which only the labor-managed firm installs excess capacity as a strategic device. This present paper extends Ohnishi's (2018) framework by examining a model of international mixed triopoly.

This paper examines a model in which there are a state-owned firm, a domestic labor-managed firm and a foreign capitalist firm. The following situation is considered. In the first stage, each firm non-cooperatively chooses its capacity level. No firms can reduce or dispose of capacity. In the second stage, each firm non-cooperatively chooses its output. We discuss the subgame perfect equilibrium of the model.

The purpose of this paper is to show the equilibrium outcome of international mixed tripoly competition where a state-owned firm, a domestic labor-managed firm and a foreign capitalist firm can install capacity as a strategic device.

The remainder of this paper is organized as follows. In Section 2, the model is described. Section 3 gives supplementary explanations of the model. Section 4 discusses the equilibrium of the model. Section 5 summarizes and concludes the paper. 


\section{Model}

There is a market composed of a domestic state-owned firm (firm S), a domestic labor-managed firm (firm DL) and a foreign capitalist firm (firm FC). In the remainder of this paper, subscripts S, DL and FC denote firm S, firm DL and firm FC, respectively. They produce perfectly substitutable goods. There is no possibility of entry or exit. The inverse demand function is represented by $P(Q)$, where $Q=q_{\mathrm{S}}+q_{\mathrm{DL}}+q_{\mathrm{FC}}$. We assume that $d P / d Q=\left(\partial P / \partial q_{\mathrm{S}}=\partial P / \partial q_{\mathrm{DL}}=\partial P / \partial q_{\mathrm{FC}}\right)$ $<0, d^{2} P / d Q^{2}=\left(\partial^{2} P / \partial q_{\mathrm{S}}^{2}=\partial^{2} P / \partial q_{\mathrm{DL}}^{2}=\partial^{2} P / \partial q_{\mathrm{FC}}^{2}\right)>0$, and $d P / d Q+q_{i} \partial^{2} P / \partial Q^{2}<0 \quad(i$ $=\mathrm{S}, \mathrm{DL}, \mathrm{FC}$ ). Note that this assumption is used in many papers of mixed oligopoly (see, for example, Stewart, 1991; Delbono and Rossini, 1992; Okuguchi, 1993; Lambertini, 1997; Lambertini and Rossini, 1998; Ohnishi, 2009).

The timing of the game is as follows. In the first stage, each firm $i(i=\mathrm{S}, \mathrm{DL}, \mathrm{FC})$ simultaneously and independently chooses its capacity level $k_{i} \geq 0$. None of the firms can reduce or dispose of capacity. At the end of the first stage, each firm observes $k_{\mathrm{S}}, k_{\mathrm{DL}}$ and $k_{\mathrm{FC}}$. In the second stage, each firm simultaneously and independently chooses its output level $q_{i} \geq 0$.

Therefore, each firm's profit is given by

$$
\pi_{i}\left(q_{\mathrm{S}}, q_{\mathrm{DL}}, q_{\mathrm{FC}}\right)= \begin{cases}P(Q) q_{i}-w\left(q_{i}\right)-r\left(q_{i}\right)-f & \text { if } q_{i}>k_{i} \\ P(Q) q_{i}-w\left(q_{i}\right)-r\left(k_{i}\right)-f & \text { if } q_{i} \leq k_{i}\end{cases}
$$

where $w$ denotes the labor cost function, $r$ is the capital cost function, and $f>0$ is the fixed cost. We assume $d w / d q_{i}>0, d^{2} w / d q_{i}^{2}>0, d r / d q_{i}>0$ and $d^{2} r / d q_{i}^{2}>0 .{ }^{1}$ Firm FC

\footnotetext{
${ }^{1}$ We assume that the firms share the same cost function and the marginal cost of production is
} 
chooses $k_{\mathrm{FC}}$ and $q_{\mathrm{FC}}$ in order to maximize its own profit.

Economic welfare, which is the sum of consumers' surplus and domestic producers' surplus, is given by

$W\left(q_{\mathrm{S}}, q_{\mathrm{DL}}, q_{\mathrm{FC}}\right)= \begin{cases}\int_{0}^{Q} P(x) d x-w\left(q_{\mathrm{S}}\right)-r\left(q_{\mathrm{S}}\right)-w\left(q_{\mathrm{DL}}\right)-r\left(q_{\mathrm{DL}}\right)-P q_{\mathrm{FC}}-3 f & \text { if } q_{\mathrm{S}}>k_{\mathrm{S}}, \\ \int_{0}^{Q} P(x) d x-w\left(q_{\mathrm{S}}\right)-r\left(k_{\mathrm{S}}\right)-w\left(q_{\mathrm{DL}}\right)-r\left(q_{\mathrm{DL}}\right)-P q_{\mathrm{FC}}-3 f & \text { if } q_{\mathrm{S}} \leq k_{\mathrm{S}} .\end{cases}$

Firm S chooses $k_{\mathrm{S}}$ and $q_{\mathrm{S}}$ in order to maximize economic welfare.

Firm DL's income per worker is given by

$$
\phi_{\mathrm{DL}}\left(q_{\mathrm{S}}, q_{\mathrm{DL}}, q_{\mathrm{FC}}\right)= \begin{cases}\frac{P(Q) q_{\mathrm{DL}}-r\left(q_{\mathrm{DL}}\right)-f}{l\left(q_{\mathrm{DL}}\right)} & \text { if } q_{\mathrm{DL}}>k_{\mathrm{DL}}, \\ \frac{P(Q) q_{\mathrm{DL}}-r\left(k_{\mathrm{DL}}\right)-f}{l\left(q_{\mathrm{DL}}\right)} & \text { if } q_{\mathrm{DL}} \leq k_{\mathrm{DL}},\end{cases}
$$

where $l>0$ denotes the labor input function. We assume that $d l / d q_{\mathrm{DL}}>0$ and $d^{2} l / d q_{\mathrm{DL}}^{2}>0$. Firm DL chooses $k_{\mathrm{DL}}$ and $q_{\mathrm{DL}}$ in order to maximize income per worker.

Firm $i$ cannot reduce and dispose of capacity. If firm $i$ installs capacity, then $r\left(k_{i}\right)$ is sunk. Therefore, if $q_{i} \leq k_{i}$, then firm $i$ 's marginal cost is $d w / d q_{i}$ and exhibits a discontinuity at $q_{i}=k_{i}$. This irreversible behavior causes changes to the quantity-setting competing environment

increasing. This assumption is often used in literature studying mixed oligopoly markets (for example, Harris and Wiens, 1980; Ware, 1986; Delbono and Rossini, 1992; Delbono and Scarpa, 1995; Fjell and Pal, 1996; White, 1996; Pal and White, 1998; Poyago-Theotoky, 1998; Fjell and Heywood, 2002; Bárcena-Ruiz and Garzón, 2003; Matsumura and Kanda, 2005; Ohnishi, 2008; Hsu, Lee and Wang, 2018). If the marginal cost of production is constant or decreasing, then firm $\mathrm{S}$ produces an output such that price equals marginal cost and results in a public monopoly. 
of the second stage and makes the capacity commitment credible as a strategic device.

In this paper, we adopt subgame perfection as our equilibrium concept. Since the inverse demand function is defined only for non-negative outputs, it is ensured that all outputs obtained in equilibrium are non-negative.

\section{Supplementary explanations}

This section gives supplementary explanations of the model described in the previous section. First, we derive firm S's reaction function from (2). If firm S's marginal cost is $d w / d q_{\mathrm{S}}+d r / d q_{\mathrm{S}}$, then its reaction function is defined by

$$
R_{\mathrm{S}}\left(q_{\mathrm{DL}}, q_{\mathrm{FC}}\right)=\arg \max _{\left\{q_{\mathrm{s}} \geq 0\right\}}\left[\int_{0}^{Q} P(x) d x-w\left(q_{\mathrm{S}}\right)-r\left(q_{\mathrm{S}}\right)-w\left(q_{\mathrm{DL}}\right)-r\left(q_{\mathrm{DL}}\right)-P q_{\mathrm{FC}}\right],
$$

and if firm $\mathrm{S}$ reduces its marginal cost to $d w / d q_{\mathrm{S}}$, then its reaction function is defined by

$$
R_{\mathrm{S}}^{k}\left(q_{\mathrm{DL}}, q_{\mathrm{FC}}\right)=\arg \max _{\left\{q_{\mathrm{S}} \geq 0\right\}}\left[\int_{0}^{Q} P(x) d x-w\left(q_{\mathrm{S}}\right)-r\left(k_{\mathrm{S}}\right)-w\left(q_{\mathrm{DL}}\right)-r\left(q_{\mathrm{DL}}\right)-P q_{\mathrm{FC}}\right] .
$$

Therefore, if firm $\mathrm{S}$ installs $k_{\mathrm{S}}$, then its best response is shown as follows:

$$
\hat{R}_{\mathrm{S}}\left(q_{\mathrm{DL}}, q_{\mathrm{FC}}\right)= \begin{cases}R_{\mathrm{S}}\left(q_{\mathrm{DL}}, q_{\mathrm{FC}}\right) & \text { if } q_{\mathrm{S}}>k_{\mathrm{S}}, \\ k_{\mathrm{S}} & \text { if } q_{\mathrm{S}}=k_{\mathrm{S}}, \\ R_{\mathrm{S}}^{k}\left(q_{\mathrm{DL}}, q_{\mathrm{FC}}\right) & \text { if } q_{\mathrm{S}}<k_{\mathrm{S}} .\end{cases}
$$

Firm S cannot reduce and dispose of capacity. This irreversible behavior causes changes to the quantity-setting competing environment, and economic welfare becomes (2). If firm S installs no capacity, then its reaction function is defined by (4). On the other hand, if firm S installs capacity and reduces its marginal cost of production, then its reaction function is defined by (5). Therefore, 
by strategic choice of capacity, firm S's best response becomes (6). Firm S's investment choice thus creates kinks in the reaction curve at the level of installed capacity.

We now present the following lemma.

Lemma 1: Under Cournot competition, firm S's reaction functions to firm DL are downward sloping, whereas firm S's reaction functions to firm FC are upward sloping.

Proof: Firm S aims to maximize economic welfare with respect to $q_{\mathrm{S}}$, given $q_{\mathrm{DL}}$ and $q_{\mathrm{FC}}$. The equilibrium needs to satisfy the following conditions. If firm S's marginal cost is $d w / d q_{\mathrm{S}}+d r / d q_{\mathrm{S}}$, the first-order condition for (4) is

$$
P-\frac{d w}{d q_{\mathrm{S}}}-\frac{d r}{d q_{\mathrm{S}}}-q_{\mathrm{FC}} \frac{d P}{d Q}=0
$$

and the second-order condition for (4) is

$$
\frac{d P}{d Q}-\frac{d^{2} w}{d q_{\mathrm{S}}^{2}}-\frac{d^{2} r}{d q_{\mathrm{S}}^{2}}-q_{\mathrm{FC}} \frac{d^{2} P}{d Q^{2}}<0
$$

Therefore, we have

$$
\frac{\partial R_{\mathrm{S}}\left(q_{\mathrm{DL}}, q_{\mathrm{FC}}\right)}{\partial q_{\mathrm{DL}}}=-\frac{d P / d Q-q_{\mathrm{FC}} d^{2} P / d Q^{2}}{d P / d Q-d^{2} w / d q_{\mathrm{S}}^{2}-d^{2} r / d q_{\mathrm{S}}^{2}-q_{\mathrm{FC}} d^{2} P / d Q^{2}}
$$

and

$$
\frac{\partial R_{\mathrm{S}}\left(q_{\mathrm{DL}}, q_{\mathrm{FC}}\right)}{\partial q_{\mathrm{FC}}}=\frac{q_{\mathrm{FC}} d^{2} P / d Q^{2}}{d P / d Q-d^{2} w / d q_{\mathrm{S}}^{2}-d^{2} r / d q_{\mathrm{S}}^{2}-q_{\mathrm{FC}} d^{2} P / d Q^{2}} .
$$

Here, $\partial R_{\mathrm{S}}\left(q_{\mathrm{DL}}, q_{\mathrm{FC}}\right) / \partial q_{\mathrm{DL}}$ is negative, and firm S's reaction function to firm DL's output slopes 
downward, whereas from (10), $\partial R_{\mathrm{S}}\left(q_{\mathrm{DL}}, q_{\mathrm{FC}}\right) / \partial q_{\mathrm{FC}}$ is positive, and firm S's reaction function to firm FC's output slopes upward.

In addition, if firm $\mathrm{S}$ reduces its marginal cost to $d w / d q_{\mathrm{S}}$, the first-order condition for (5) is

$$
P-\frac{d w}{d q_{\mathrm{S}}}-q_{\mathrm{FC}} \frac{d P}{d Q}=0
$$

and the second-order condition for (5) is

$$
\frac{d P}{d Q}-\frac{d^{2} w}{d q_{\mathrm{S}}^{2}}-q_{\mathrm{FC}} \frac{d^{2} P}{d Q^{2}}<0
$$

Therefore, we have

$$
\frac{\partial R_{\mathrm{S}}\left(q_{\mathrm{DL}}, q_{\mathrm{FC}}\right)}{\partial q_{\mathrm{DL}}}=-\frac{d P / d Q-q_{\mathrm{FC}} d^{2} P / d Q^{2}}{d P / d Q-d^{2} w / d q_{\mathrm{S}}^{2}-q_{\mathrm{FC}} d^{2} P / d Q^{2}}
$$

and

$$
\frac{\partial R_{\mathrm{S}}\left(q_{\mathrm{DL}}, q_{\mathrm{FC}}\right)}{\partial q_{\mathrm{FC}}}=\frac{q_{\mathrm{FC}} d^{2} P / d Q^{2}}{d P / d Q-d^{2} w / d q_{\mathrm{S}}^{2}-q_{\mathrm{FC}} d^{2} P / d Q^{2}} .
$$

Here, $\partial R_{\mathrm{S}}\left(q_{\mathrm{DL}}, q_{\mathrm{FC}}\right) / \partial q_{\mathrm{DL}}$ is negative, and firm S's reaction function to firm DL's output slopes downward, whereas from (14), firm S's reaction function to firm FC's output is upward sloping. Q.E.D.

Second, we derive firm DL's reaction function from (3). If firm DL does not install capacity, then its reaction function is defined by

$$
R_{\mathrm{DL}}\left(q_{\mathrm{S}}, q_{\mathrm{FC}}\right)=\arg \max _{\left\{q_{\mathrm{DL}} \geq 0\right\}}\left[\frac{P(Q) q_{\mathrm{DL}}-r\left(q_{\mathrm{DL}}\right)-f}{l\left(q_{\mathrm{DL}}\right)}\right],
$$


and if firm DL installs $k_{\mathrm{DL}}$ and produces $q_{\mathrm{DL}} \leq k_{\mathrm{DL}}$, then its reaction function is defined by

$$
R_{\mathrm{DL}}^{k}\left(q_{\mathrm{S}}, q_{\mathrm{FC}}\right)=\arg \max _{\left\{q_{\mathrm{DL}} \geq 0\right\}}\left[\frac{P(Q) q_{\mathrm{DL}}-r\left(k_{\mathrm{DL}}\right)-f}{l\left(q_{\mathrm{DL}}\right)}\right] .
$$

Therefore, if firm DL installs $k_{\mathrm{DL}}$, then its best response is as follows:

$$
\hat{R}_{\mathrm{DL}}\left(q_{\mathrm{S}}, q_{\mathrm{FC}}\right)= \begin{cases}R_{\mathrm{DL}}\left(q_{\mathrm{S}}, q_{\mathrm{FC}}\right) & \text { if } q_{\mathrm{DL}}>k_{\mathrm{DL}} \\ k_{\mathrm{DL}} & \text { if } q_{\mathrm{DL}}=k_{\mathrm{DL}} \\ R_{\mathrm{DL}}^{k}\left(q_{\mathrm{S}}, q_{\mathrm{FC}}\right) & \text { if } q_{\mathrm{DL}}<k_{\mathrm{DL}}\end{cases}
$$

We now state the following lemma.

Lemma 2: Under Cournot competition, both $R_{\mathrm{DL}}$ and $R_{\mathrm{DL}}^{k}$ are upward sloping.

Proof: Firm DL seeks to maximize income per worker with respect to $q_{\mathrm{DL}}$, given $q_{\mathrm{S}}$ and $q_{\mathrm{FC}}$. The equilibrium solution satisfies the following conditions. The first-order condition for (15) is

$$
\left(q_{\mathrm{DL}} \frac{d P}{d Q}+P-\frac{d r}{d q_{\mathrm{DL}}}\right) l-\left(P q_{\mathrm{DL}}-r-f\right) \frac{d l}{d q_{\mathrm{DL}}}=0,
$$

and the second-order condition for (15) is

$$
\left(q_{\mathrm{DL}} \frac{d^{2} P}{d Q^{2}}+2 \frac{d P}{d Q}-\frac{d^{2} r}{d q_{\mathrm{DL}}^{2}}\right) l-\left(P q_{\mathrm{DL}}-r-f\right) \frac{d^{2} l}{d q_{\mathrm{DL}}^{2}}<0 .
$$

Moreover, we obtain

$$
\begin{aligned}
& \frac{\partial R_{\mathrm{DL}}\left(q_{\mathrm{S}}, q_{\mathrm{FC}}\right)}{\partial q_{\mathrm{S}}}=\frac{\partial R_{\mathrm{DL}}\left(q_{\mathrm{S}}, q_{\mathrm{FC}}\right)}{\partial q_{\mathrm{FC}}} \\
& =-\frac{q_{\mathrm{DL}} l d^{2} P / d Q^{2}+\left(l-q_{\mathrm{DL}} d l / d q_{\mathrm{DL}}\right) d P / d Q}{\left(q_{\mathrm{DL}} d^{2} P / d Q^{2}+2 d P / d Q-d^{2} r / d q_{\mathrm{DL}}^{2}\right) l-\left(P q_{\mathrm{DL}}-r-f\right) d^{2} l / d q_{\mathrm{DL}}^{2}} .
\end{aligned}
$$

In addition, the first-order condition for (16) is 


$$
\left(q_{\mathrm{DL}} \frac{d P}{d Q}+P\right) l-\left(P q_{\mathrm{DL}}-f\right) \frac{d l}{d q_{\mathrm{DL}}}=0
$$

and the second-order condition for (16) is

$$
\left(q_{\mathrm{DL}} \frac{d^{2} P}{d Q^{2}}+2 \frac{d P}{d Q}\right) l-\left(P q_{\mathrm{DL}}-f\right) \frac{d^{2} l}{d q_{\mathrm{DL}}^{2}}<0
$$

Therefore, we obtain

$$
\frac{\partial R_{\mathrm{DL}}^{k}\left(q_{\mathrm{S}}, q_{\mathrm{FC}}\right)}{\partial q_{\mathrm{S}}}=\frac{\partial R_{\mathrm{DL}}^{k}\left(q_{\mathrm{S}}, q_{\mathrm{FC}}\right)}{\partial q_{\mathrm{FC}}}=-\frac{q_{\mathrm{DL}} l d^{2} P / d Q^{2}+\left(l-q_{\mathrm{DL}} d l / d q_{\mathrm{DL}}\right) d P / d Q}{\left(q_{\mathrm{DL}} d^{2} P / d Q^{2}+2 d P / d Q\right) l-\left(P q_{\mathrm{DL}}-f\right) d^{2} l / d q_{\mathrm{DL}}^{2}}
$$

Since $d^{2} l / d q_{\mathrm{DL}}^{2}>0, \quad l-q_{\mathrm{DL}} d l / d q_{\mathrm{DL}}<0$, so that $q_{\mathrm{DL}} l d^{2} P / d Q^{2}+\left(l-q_{\mathrm{DL}} d l / d q_{\mathrm{DL}}\right)$ $d P / d Q$ is positive. Q.E.D.

Third, we derive firm FC's reaction function from (1). If firm FC's marginal cost is $d w / d q_{\mathrm{FC}}+d r / d q_{\mathrm{FC}}$, then its reaction function is defined by

$$
R_{\mathrm{FC}}\left(q_{\mathrm{S}}, q_{\mathrm{DL}}\right)=\arg \max _{\left\{q_{\mathrm{FC}} \geq 0\right\}}\left[p(Q) q_{\mathrm{FC}}-w\left(q_{\mathrm{FC}}\right)-r\left(q_{\mathrm{FC}}\right)-f\right]
$$

and if firm FC reduces its marginal cost to $d w / d q_{\mathrm{FC}}$, then its reaction function is defined by

$$
R_{\mathrm{FC}}^{k}\left(q_{\mathrm{S}}, q_{\mathrm{DL}}\right)=\arg \max _{\left\{q_{\mathrm{FC}} \geq 0\right\}}\left[p(Q) q_{\mathrm{FC}}-w\left(q_{\mathrm{FC}}\right)-r\left(k_{\mathrm{FC}}\right)-f\right]
$$

Therefore, if firm FC installs $k_{\mathrm{FC}}$, then its best response changes as follows:

$$
\hat{R}_{\mathrm{FC}}\left(q_{\mathrm{S}}, q_{\mathrm{DL}}\right)= \begin{cases}R_{\mathrm{FC}}\left(q_{\mathrm{S}}, q_{\mathrm{DL}}\right) & \text { if } q_{\mathrm{FC}}>k_{\mathrm{FC}} \\ k_{\mathrm{FC}} & \text { if } q_{\mathrm{FC}}=k_{\mathrm{FC}} \\ R_{\mathrm{FC}}^{k}\left(q_{\mathrm{S}}, q_{\mathrm{DL}}\right) & \text { if } q_{\mathrm{FC}}<k_{\mathrm{FC}}\end{cases}
$$

We present the following lemma. 
Lemma 3: Under Cournot competition, both $R_{\mathrm{FC}}$ and $R_{\mathrm{FC}}^{k}$ are downward sloping.

Proof: Firm FC aims to maximize its profit with respect to $q_{\mathrm{FC}}$, given $q_{\mathrm{S}}$ and $q_{\mathrm{DL}}$. The equilibrium outcome needs to satisfy the following conditions: The first-order condition for (24) is

$$
q_{\mathrm{FC}} \frac{d P}{d Q}+P-\frac{d w}{d q_{\mathrm{FC}}}-\frac{d r}{d q_{\mathrm{FC}}}=0
$$

and the second-order condition for (24) is

$$
q_{\mathrm{FC}} \frac{d^{2} P}{d Q^{2}}+2 \frac{d P}{d Q}-\frac{d^{2} w}{d q_{\mathrm{FC}}^{2}}-\frac{d^{2} r}{d q_{\mathrm{FC}}^{2}}<0
$$

Moreover, we obtain

$$
\frac{\partial R_{\mathrm{FC}}\left(q_{\mathrm{S}}, q_{\mathrm{DL}}\right)}{\partial q_{\mathrm{S}}}=\frac{\partial R_{\mathrm{FC}}\left(q_{\mathrm{S}}, q_{\mathrm{DL}}\right)}{\partial q_{\mathrm{DL}}}=-\frac{d P / d Q+q_{\mathrm{FC}} d^{2} P / d Q^{2}}{2 d P / d Q+q_{\mathrm{FC}} d^{2} P / d Q^{2}-d^{2} w / d q_{\mathrm{FC}}^{2}-d^{2} r / d q_{\mathrm{FC}}^{2}},
$$

where $d P / d Q+q_{\mathrm{FC}} d^{2} P / d Q^{2}<0$.

In addition, the first-order condition for (25) is

$$
q_{\mathrm{FC}} \frac{d P}{d Q}+P-\frac{d r}{d q_{\mathrm{FC}}}=0
$$

and the second-order condition for $(25)$ is

$$
q_{\mathrm{FC}} \frac{d^{2} P}{d Q^{2}}+2 \frac{d P}{d Q}-\frac{d^{2} r}{d q_{\mathrm{FC}}^{2}}<0
$$

Therefore, we obtain

$$
\frac{\partial R_{\mathrm{FC}}^{k}\left(q_{\mathrm{S}}, q_{\mathrm{DL}}\right)}{\partial q_{\mathrm{S}}}=\frac{\partial R_{\mathrm{FC}}^{k}\left(q_{\mathrm{S}}, q_{\mathrm{DL}}\right)}{\partial q_{\mathrm{DL}}}=-\frac{d P / d Q+q_{\mathrm{FC}} d^{2} P / d Q^{2}}{2 d P / d Q+q_{\mathrm{FC}} d^{2} P / d Q^{2}-d^{2} r / d q_{\mathrm{FC}}^{2}}
$$

where $d P / d Q+q_{\mathrm{FC}} d^{2} P / d Q^{2}<0$. Q.E.D. 
Fourth, we present the following lemmas, which provide characterizations of capacity as a strategic commitment device.

Lemma 4: Firm $i$ 's optimal output is higher when it installs capacity than when it does not.

Proof: We prove that firm S's welfare-maximizing output is larger when it installs capacity than when it does not. From (2), we see that capacity investment will never increase firm S's marginal cost of production. When firm S's marginal cost of production is $d w / d q_{\mathrm{S}}+d r / d q_{\mathrm{S}}$, the first-order condition is (7), and when its marginal cost of production is $d w / d q_{\mathrm{S}}$, the first-order condition is (11). Here, $d r / d q_{\mathrm{S}}$ is positive. To satisfy (7), $P-d w / d q_{\mathrm{S}}-q_{\mathrm{FC}} d P / d Q$ must be positive. Thus, firm S's welfare-maximizing output is larger when its marginal cost is $d w / d q_{\mathrm{S}}$ than when its marginal cost is $d w / d q_{\mathrm{S}}+d r / d q_{\mathrm{S}}$.

The proofs for firm DL and firm FC are omitted, since they are similar to the above proof of this lemma. Q.E.D.

Lemma 5: If firm $i$ installs $k_{i}$ and an equilibrium solution is achieved, then at equilibrium $q_{i}=k_{i}$

Proof: We prove that if firm DL installs capacity, then at equilibrium $q_{\mathrm{DL}}=k_{\mathrm{DL}}$. Consider the 
possibility that $q_{\mathrm{DL}}<k_{\mathrm{DL}}$ at equilibrium. From (3), when firm DL installs capacity, its income per worker is

$$
\phi_{\mathrm{DL}}\left(q_{\mathrm{S}}, q_{\mathrm{DL}}, q_{\mathrm{FC}}\right)=\frac{P(Q) q_{\mathrm{DL}}-r\left(k_{\mathrm{DL}}\right)-f}{l\left(q_{\mathrm{DL}}\right)}
$$

Here, since $q_{\mathrm{DL}}<k_{\mathrm{DL}}$, firm DL installs the extra capacity. However, firm DL can increase income per worker by reducing $k_{\mathrm{DL}}$, and the equilibrium point does not change in $q_{\mathrm{DL}} \leq k_{\mathrm{DL}}$. Hence, $q_{\mathrm{DL}}<k_{\mathrm{DL}}$ does not result in an equilibrium solution.

Consider the possibility that $q_{\mathrm{DL}}>k_{\mathrm{DL}}$ at equilibrium. From (3), we see that it is impossible for firm DL to change its output at equilibrium because such a strategy is not credible. That is, capacity investment does not function as a strategic commitment.

The proofs for firm $\mathrm{S}$ and firm FC are similar, so they are omitted. Q.E.D.

Lemma 4 means that if firm $i$ installs capacity in advance of production, then its optimal output increases. Lemma 5 indicates that at equilibrium firm $i$ does not install extra capacity.

\section{Equilibrium}

We first discuss the possibility in which only firm FC installs excess capacity. Firm FC aims to maximize its own profit. Therefore, it is thought that firm FC will install capacity if its profit increases by doing so, while firm FC will not install capacity if its profit decreases by doing so. 
Firm FC's investment choice decreases its marginal cost and increases its output. Firm FC cannot reduce or dispose of capacity. This irreversible behavior causes changes to the quantity-setting competing environment of the second stage, and firm FC's profit becomes (1). Therefore, firm FC's best response becomes (9).

The installation of capacity by firm FC increases its optimal output (Lemma 4). Given firm S's and firm DL's output, increasing firm FC's output increases the total market output, thereby increasing economic welfare. Furthermore, firm S's optimal strategy must yield at least this economic welfare. Increasing firm FC's output increases firm S's output (Lemma 1), increasing firm S's output decreases firm FC's output (Lemma 3), thereby decreasing firm FC's profit.

In addition, increasing firm FC's output increases firm DL's output (Lemma 2), and increasing firm DL's output decreases firm FC's output (Lemma 3). This also decreases firm FC's profit.

We can state the following proposition.

Proposition 1: Suppose that only firm FC installs excess capacity. Then, (i) firm FC's profit falls, (ii) economic welfare rises, and (iii) firm DL's income per worker falls.

Proof: See the appendix.

Second, we consider the possibility in which only firm DL installs excess capacity. Firm DL aims to maximize income per worker. Therefore, it is thought that firm DL will install capacity if its 
income per worker increases by doing so, while firm DL will not install capacity if its income per worker decreases by doing so. Firm DL's investment choice decreases its marginal cost and increases its output. Firm DL cannot reduce or dispose of capacity. This irreversible behavior causes changes to the Cournot competing environment of stage two. Firm DL's income per worker becomes (3), and therefore firm DL's best response is (12).

The installation of capacity by firm DL increases its optimal output (Lemma 4). Given firm FC's output level, increasing firm DL's output increases the total market output and lowers the price, thereby decreasing firm FC's profit. Furthermore, firm FC's optimal strategy decreases its output because of strategic substitutes. This increases firm DL's income per worker.

The installation of capacity by firm DL increases its optimal output (Lemma 4). Given firm S's and firm FC's output levels, increasing firm DL's output increases the total market output and also increases economic welfare. Furthermore, firm S's optimal strategy must yield at least this economic welfare. Increasing firm DL's output decreases firm S's output (Lemma 1), thereby increasing firm DL's income per worker.

We state the following proposition.

Proposition 2: Suppose that only firm DL installs excess capacity. Then, (i) firm DL's income per worker rises, (ii) economic welfare rises, and (iii) firm FC's profit falls.

Proof: See the appendix. 
Third, we consider the possibility in which only firm $\mathrm{S}$ installs excess capacity. Firm $\mathrm{S}$ aims to maximize economic welfare. Therefore, it is thought that firm $\mathrm{S}$ will install capacity if economic welfare increases by doing so, while firm $\mathrm{S}$ will not install capacity if economic welfare decreases by doing so. Firm S's investment choice decreases its marginal cost and increases its output. Firm S cannot reduce or dispose of capacity. Economic welfare becomes (2), and hence firm S's best response becomes (6).

The installation of capacity by firm S increases its optimal output (Lemma 4). Given firm DL's and firm FC's output, increasing firm S's output increases the total output and lowers the price, thereby decreasing firm FC's profit and firm DL's income per worker. Firm FC decreases its optimal output by strategic substitutes. This also decreases economic welfare. On the other hand, firm DL increases its optimal output by strategic complements, thereby improving economic welfare.

Proposition 3: Suppose that only firm S installs excess capacity. Then, (i) economic welfare may rise or fall, (ii) firm DL's income per worker falls, and (iii) firm FC's profit falls.

Proof: See the appendix.

Proposition 1 means that there may be no possibility in which firm FC installs excess capacity. 
Proposition 2 indicates that firm DL installs excess capacity if firm S and firm FC do not. Proposition 3 states that unilateral capacity installation by firm S decreases firm DL's income per worker and firm FC's profit.

We now state the main result of this study in the following proposition.

Proposition 4: In the international mixed triopoly model, there is an equilibrium solution where only firm DL installs excess capacity. At equilibrium, economic welfare and firm DL's income per worker are higher than in the quantity-setting game with no capacity, whereas firm FC's profit is lower than in the quantity-setting game with no capacity.

Proof: See the appendix.

\section{Conclusion}

We have examined a mixed triopoly model in which a state-owned firm, a domestic labor-managed firm and a foreign capitalist firm are allowed to install capacity as a strategic device. We have shown that there is an equilibrium solution where only the domestic labor-managed firm pre-installs excess capacity as a strategic device. As a result of this analysis, we find that excess capacity is an effective strategy for state-owned and domestic labor-managed firms in the international mixed triopoly regime. 


\section{Appendix: Proofs of Propositions 1-4}

We begin by proving the following supplementary lemmas.

Lemma A1: Firm FC's Stackelberg leader output is lower than its Cournot output.

Proof: When firm FC is a Stackelberg leader, it maximizes $\pi_{\mathrm{FC}}\left(q_{\mathrm{FC}}, R_{\mathrm{DL}}\left(q_{\mathrm{FC}}\right), R_{\mathrm{S}}\left(q_{\mathrm{FC}}\right)\right)$ with respect to $q_{\mathrm{FC}}$. The first-order condition for Stackelberg profit maximization is

$$
q_{\mathrm{FC}} \frac{d P}{d Q}+P-\frac{d w}{d q_{\mathrm{FC}}}-\frac{d r}{d q_{\mathrm{FC}}}+q_{\mathrm{FC}} \frac{d P}{d Q} \frac{\partial R_{\mathrm{DL}}}{\partial q_{\mathrm{FC}}}+q_{\mathrm{FC}} \frac{d P}{d Q} \frac{\partial R_{\mathrm{S}}}{\partial q_{\mathrm{FC}}}=0
$$

where $d P / d Q<0, \partial R_{\mathrm{DL}} / \partial q_{\mathrm{FC}}>0$ (Lemma 2), and $\partial R_{\mathrm{S}} / \partial q_{\mathrm{FC}}>0$ (Lemma 1). To satisfy (33), $q_{\mathrm{FC}}(d P / d Q)+P-d w / d q_{\mathrm{FC}}-d r / d q_{\mathrm{FC}}$ must be positive. Hence, Lemma A1 is proved. Q.E.D.

Lemma A2: Firm DL's Stackelberg leader output is higher than its Cournot output.

Proof: If firm DL is a Stackelberg leader, then it maximizes $\phi_{\mathrm{DL}}\left(q_{\mathrm{DL}}, R_{\mathrm{FC}}\left(q_{\mathrm{DL}}\right), R_{\mathrm{S}}\left(q_{\mathrm{DL}}\right)\right)$ with respect to $q_{\mathrm{DL}}$, and the first-order condition is 


$$
\left(q_{\mathrm{DL}} \frac{d P}{d Q}+P-\frac{d r}{d q_{\mathrm{DL}}}\right) l-\left(P q_{\mathrm{DL}}-r-f\right) \frac{d l}{d q_{\mathrm{DL}}}+q_{\mathrm{DL}} \frac{d P}{d Q} \frac{\partial R_{\mathrm{FC}}}{\partial q_{\mathrm{DL}}} l+q_{\mathrm{DL}} \frac{d P}{d Q} \frac{\partial R_{\mathrm{S}}}{\partial q_{\mathrm{DL}}} l=0,
$$

where $d P / d Q<0, \partial R_{\mathrm{FC}} / \partial q_{\mathrm{DL}}<0$ (Lemma 3), and $\partial R_{\mathrm{S}} / \partial q_{\mathrm{DL}}<0$ (Lemma 1). To satisfy (34), $\left(q_{\mathrm{DL}} d P / d Q+P-d r / d q_{\mathrm{DL}}\right) l-\left(P q_{\mathrm{DL}}-r-f\right) d l / d q_{\mathrm{DL}}$ must be negative. Thus, Lemma A2 follows. Q.E.D.

Lemma A3: Firm S's Stackelberg leader output may be higher or lower than its Cournot output.

Proof: When firm $\mathrm{S}$ is a Stackelberg leader, it maximizes $W\left(R_{\mathrm{FC}}\left(q_{\mathrm{S}}\right), R_{\mathrm{DL}}\left(q_{\mathrm{S}}\right), q_{\mathrm{S}}\right)$ with respect to $q_{\mathrm{S}}$, and the first-order condition for welfare maximization is

$$
P-\frac{d w}{d q_{\mathrm{S}}}-\frac{d r}{d q_{\mathrm{S}}}+q_{\mathrm{S}} \frac{d P}{d Q} \frac{\partial R_{\mathrm{FC}}}{\partial q_{\mathrm{S}}}+q_{\mathrm{S}} \frac{d P}{d Q} \frac{\partial R_{\mathrm{DL}}}{\partial q_{\mathrm{S}}}=0
$$

where $d P / d Q<0, \partial R_{\mathrm{FC}} / \partial q_{\mathrm{S}}<0$ (Lemma 3), and $\partial R_{\mathrm{DL}} / \partial q_{\mathrm{S}}>0$ (Lemma 2). If $\partial R_{\mathrm{FC}} / \partial q_{\mathrm{S}}+\partial R_{\mathrm{DL}} / \partial q_{\mathrm{S}}>0$, then firm S's Stackelberg leader output exceeds its Cournot output, and if $\partial R_{\mathrm{FC}} / \partial q_{\mathrm{S}}+\partial R_{\mathrm{DL}} / \partial q_{\mathrm{S}}<0$, the large/small relation is reverse. Q.E.D.

We now prove Propositions 1-4.

\section{Proof of Proposition 1}

(i) Firm FC's Stackelberg leader output is lower than its Cournot output (Lemma A1). Moreover, $\pi_{\mathrm{FC}}\left(q_{\mathrm{S}}, q_{\mathrm{DL}}, q_{\mathrm{FC}}\right)=P(Q) q_{\mathrm{FC}}-w\left(q_{\mathrm{FC}}\right)-r\left(q_{\mathrm{FC}}\right)-f$ is continuous and concave with respect to 
$q_{\mathrm{DC}}$. The farther firm FC's output gets from firm its Stackelberg leader output, the more its profit decreases. However, firm FC's profit maximizing output when it installs capacity is larger than that when it does not (Lemma 4). Given firm S's and firm DL's output, increasing firm FC's output increases the total market output and lowers the price. However, firm S's and firm DL's optimal strategies increase their outputs because of strategic complements, thereby decreasing firm FC's profit.

(ii) Proposition 1 (ii) is true because $\partial W\left(q_{\mathrm{S}}, q_{\mathrm{DL}}, q_{\mathrm{FC}}\right) / \partial q_{\mathrm{FC}}=-P^{\prime} q_{\mathrm{FC}}>0$.

(iii) Proposition 1 (iii) follows because $\partial \phi_{\mathrm{DL}}\left(q_{\mathrm{S}}, q_{\mathrm{DL}}, q_{\mathrm{FC}}\right) / \partial q_{\mathrm{FC}}=q_{\mathrm{DL}} d P / d Q<0$. Q.E.D.

\section{Proof of Proposition 2}

(i) Firm DL's Stackelberg leader output is higher than its Cournot output (Lemma A2). Moreover, $\phi_{\mathrm{DL}}\left(q_{\mathrm{S}}, q_{\mathrm{DL}}, q_{\mathrm{FC}}\right)=\left[P(Q) q_{\mathrm{DL}}-r\left(q_{\mathrm{DL}}\right)-f\right] / l\left(q_{\mathrm{DL}}\right)$ is continuous and concave in $q_{\mathrm{DC}}$. The farther firm DL's output gets from its Stackelberg leader output, the more its income per worker decreases. Firm DL's optimal output when it installs capacity is larger than that when it does not

(Lemma 4). When firm DL installs $k_{\mathrm{DL}}$ and an equilibrium solution is achieved, at equilibrium $q_{\mathrm{DL}}=k_{\mathrm{DL}}$ (Lemma 5). Hence, Proposition 2 (i) is true.

(ii) Proposition 2 (ii) follows because $\partial W\left(q_{\mathrm{S}}, q_{\mathrm{DL}}, q_{\mathrm{FC}}\right) / \partial q_{\mathrm{DL}}=P-d w / d q_{\mathrm{DL}}-d r / d q_{\mathrm{DL}}>0$.

(iii) Proposition 2 (iii) follows because $\partial \pi_{\mathrm{FC}}\left(q_{\mathrm{S}}, q_{\mathrm{DL}}, q_{\mathrm{FC}}\right) / \partial q_{\mathrm{DL}}=q_{\mathrm{FC}} d P / d Q<0$. Q.E.D. 


\section{Proof of Proposition 3}

(i) Firm S's Stackelberg leader output may be higher or lower than its Cournot output (Lemma A3).

Firm S's welfare-maximizing output when it installs capacity is larger than that when it does not

(Lemma 4). If $q_{\mathrm{S}}(d P / d Q)\left(\partial R_{\mathrm{DL}} / \partial q_{\mathrm{S}}\right)+q_{\mathrm{S}}(d P / d Q)\left(\partial R_{\mathrm{FC}} / \partial q_{\mathrm{S}}\right)<0$, then $P-d w / d q_{\mathrm{S}}-$ $d r / d q_{\mathrm{S}}>0$, and therefore economic welfare falls by installing excess capacity. On the other hand, if $q_{\mathrm{S}}(d P / d Q)\left(\partial R_{\mathrm{DL}} / \partial q_{\mathrm{S}}\right)+q_{\mathrm{S}}(d P / d Q)\left(\partial R_{\mathrm{FC}} / \partial q_{\mathrm{S}}\right)>0$, then $P-d w / d q_{\mathrm{S}}-d r / d q_{\mathrm{S}}<0$, and therefore economic welfare rises.

(ii) Proposition 3 (ii) is true because $\partial \phi_{\mathrm{DL}}\left(q_{\mathrm{S}}, q_{\mathrm{DL}}, q_{\mathrm{FC}}\right) / \partial q_{\mathrm{S}}=q_{\mathrm{DL}} d P / d Q<0$.

(iii) Proposition 3 (iii) is true because $\partial \pi_{\mathrm{FC}}\left(q_{\mathrm{S}}, q_{\mathrm{DL}}, q_{\mathrm{FC}}\right) / \partial q_{\mathrm{DL}}=q_{\mathrm{FC}} d P / d Q<0$. Q.E.D.

\section{Proof of Proposition 4}

We first prove each firm's strategy, and then prove the second half of the proposition.

\section{Firm DL’s Strategy}

Firm DL's Stackelberg leader output is higher than its Cournot output (Lemma A2). Furthermore, $\phi_{\mathrm{DL}}=\left(p(Q) q_{\mathrm{DL}}-r\left(q_{\mathrm{DL}}\right)-f\right) / l\left(q_{\mathrm{DL}}\right)$ is continuous and concave in $q_{\mathrm{DL}}$. The farther firm DL's output gets from firm its Stackelberg leader output, the more its income per worker decreases.

Lemma 4 states that firm DL's income-per-worker-maximizing output is larger when it installs capacity than when it does not. Given firm S's and firm FC's output, increasing firm DL's output increases the total market output and lowers the price. However, firm FC's and firm S's optimal 
strategies decrease their outputs because of strategic substitutes, thereby increasing firm DL's income per worker. Hence, firm DL installs the appropriate level of capacity.

\section{Firm FC's Strategy}

Firm FC's Stackelberg leader output is lower than its Cournot output (Lemma A1). Furthermore, $\pi_{\mathrm{FC}}=p(Q) q_{\mathrm{FC}}-w\left(q_{\mathrm{FC}}\right)-r\left(q_{\mathrm{FC}}\right)-f$ is continuous and concave with respect to $q_{\mathrm{FC}}$. In $R_{\mathrm{DL}}$, firm FC's profit is highest at firm FC's Stackelberg leader point, and the farther the point on $R_{\mathrm{DL}}$ gets from firm FC's Stackelberg leader point, the more firm FC's profit decreases. Lemma 4 states that firm FC's profit-maximizing output when it installs capacity is larger than that when it does not.

Next, we consider the possibility that both firm FP and firm DL install capacity. From (17), we see that firm DL's reaction function has a flat segment at $k_{\mathrm{DL}}$ level. Lemma 4 states that firm DL's income-per-worker-maximizing output is larger when it installs capacity than when it does not. A little increase in firm FC's output does not change firm DL's output, and therefore this decreases firm FC's profit. That is, firm FC's capacity installation decreases its own profit. Hence, firm FC has no incentive to install capacity.

\section{Firm Ss Strategy}

Firm S's Stackelberg leader output may be higher or lower than its Cournot output (Lemma A3).

Furthermore, $\quad W=\int_{0}^{Q} p(x) d x-w\left(q_{\mathrm{S}}\right)-r\left(q_{\mathrm{S}}\right)-w\left(q_{\mathrm{DL}}\right)-r\left(q_{\mathrm{DL}}\right)-P q_{\mathrm{FC}}-3 f$ is continuous 
and concave with respect to $q_{\mathrm{S}}$. In $R_{\mathrm{FC}}$, economic welfare is the highest at firm S's Stackelberg leader point. However, Lemma 4 states that firm S's welfare maximizing output when it installs capacity is larger than that when it does not.

At the end of the first stage, firm S observes $k_{\mathrm{DL}}>0$. From (17), we see that if firm DL installs $k_{\mathrm{DL}}$, then its reaction function will have a flat segment at $k_{\mathrm{DL}}$ level. Firm S's capacity installation increases its optimal output (Lemma 4). A little increase in firm S's output does not change firm DL's output, thereby decreasing economic welfare. That is, firm S's capacity installation decreases economic welfare. Hence, firm $\mathrm{S}$ has no incentive to install capacity.

\section{Payoffs}

The installation of capacity by firm DL increases its optimal output (Lemma 4). Given firm S's and firm FC's output, increasing firm DL's output increases the total market output and lowers the price. However, firm FC's and firm S's optimal strategies decrease their outputs because of strategic substitutes. Lemma 5 shows that if firm DL installs $k_{\mathrm{DL}}$ and an equilibrium is achieved, then at equilibrium $q_{\mathrm{DL}}=k_{\mathrm{DL}}$. Hence, firm DL increases income per worker.

The installation of capacity by firm DL increases $q_{\mathrm{DL}}$. Since $\partial \pi_{\mathrm{FC}}\left(q_{\mathrm{S}}, q_{\mathrm{DL}}, q_{\mathrm{FC}}\right) / \partial q_{\mathrm{DL}}=$ $q_{\mathrm{FC}} d P / d Q<0$, increasing $q_{\mathrm{DL}}$ decreases $\pi_{\mathrm{FC}}$ given $q_{\mathrm{S}}$ and $q_{\mathrm{FC}} \cdot$ In addition, since $\partial W\left(q_{\mathrm{S}}, q_{\mathrm{DL}}, q_{\mathrm{FC}}\right) / \partial q_{\mathrm{DL}}=P-d w / d q_{\mathrm{DL}}-d r / d q_{\mathrm{DL}}>0$, increasing $q_{\mathrm{DL}}$ increases $W$ given $q_{\mathrm{S}}$ and $q_{\mathrm{FC}}$. Thus, Proposition 4 is true. Q.E.D. 


\section{References}

Aguerrevere, F. L., 2009. Real options, product market competition, and asset returns. Journal of Finance 64, 957-983.

Artz, B., Heywood, J. S., McGinty, M., 2009. The merger paradox in a mixed oligopoly. Research in Economics 63, 1-10.

Askildsen, J. E., Ireland, N. J., 1993. Human capital, property right, and labour managed firms. Oxford Economic Papers 45, 229-242.

Bagwell, K., Ramey, G, 1996. Capacity, entry, and forward induction. Rand Journal of Economics $27,660-680$.

Bárcena-Ruiz, J. C., 2007. Endogenous timing in a mixed duopoly: Price competition. Journal of Economics 91, 263-272.

Bárcena-Ruiz, J. C., Garzón, M. B., 2003. Mixed duopoly, merger and multiproduct firms. Journal of Economics 80, 27-42.

Barcena-Ruiz, J. C., Garzón, M. B., 2007. Capacity choice in a mixed duopoly under price competition. Economics Bulletin 12, 1-7.

Basu, K., Singh, N., 1985 Commitment and entry-deterrence in a model of duopoly. Economics Letters 18, 265-269.

Basu, K., Singh, N., 1990. Entry-deterrence in Stackelberg perfect equilibria. International Economic Review 31, 61-71. 
Beladi, H., Chao, C.-C., 2006. Does privatization improve the environment? Economics Letters 93, 343-347.

Bulow, J., Geanakoplos, J., Klemperer, P., 1985a. Holding idle capacity to deter entry. Economic Journal 95, 178-182.

Bulow, J., Geanakoplos, J., Klemperer, P., 1985b. Multimarket oligopoly: strategic substitutes and complements. Journal of Political Economy 93, 488-511.

Chao, C.-C., Yu, E. S. H., 2006. Partial privatization, foreign competition, and optimal tariff. Review of International Economics 14, 87-92.

Cremer, H., Crémer, J., 1992. Duopoly with employee-controlled and profit-maximizing firms: Bertrand vs Cournot competition. Journal of Comparative Economics 16, 241-258.

Cremer, H., Marchand, M., Thisse, J.-F., 1989. The public firm as an instrument for regulating an oligopolistic market. Oxford Economic Papers 41, 283-301.

Cremer, H., Marchand, M., Thisse, J.-F., 1991. Mixed oligopoly with differentiated products. International Journal of Industrial Organization 9, 43-53.

Cuccia, T., Cellini, R., 2009. Workers' enterprises and the taste for production: the arts, sport and other cases. Scottish Journal of Political Economy 56, 123-137.

Delbono, F., Lambertini, L., 2018. The socially efficient firms' mix in a duopoly with environmental externalities. In Kazuhiro Ohnishi ed., Firms' Strategic Decisions: Theoretical and Empirical Findings, Volume 3 (pp. 59-68). Bentham Science Publishers, Sharjah, UAE.

Delbono, F., Rossini, G, 1992. Competition policy vs horizontal merger with public entrepreneurial, 
and labor-managed firms. Journal of Comparative Economics 16, 226-240.

Delbono, F., Scarpa, C., 1995. Upward-sloping reaction functions under quantity competition in mixed oligopolies. Bulletin of Economic Research 47, 341-346.

Dixit, A. K., 1979. A model of duopoly suggesting a theory of entry barrier. Bell Journal of Economics 17, 377-388.

Dixit, A. K., 1980. The role of investment in entry-deterrence. Economic Journal 90, 95-106.

Eaton, B., Lipsey, R., 1981. Capital, commitment and entry equilibrium. Bell Journal of Economics $12,593-604$.

Fjell, K., Heywood, J. S., 2002. Public Stackelberg leadership in a mixed oligopoly with foreign firms. Australian Economic Papers 41, 267-281.

Fjell, K., Pal, D., 1996. A mixed oligopoly in the presence of foreign private firms. Canadian Journal of Economics 29, 737-743.

George, K., La Manna, M., 1996. Mixed duopoly, inefficiency, and public ownership. Review of Industrial Organization 11, 853-860.

Grenadier, S. R., 2002. Option exercise games: an application to the equilibrium investment strategies of firms. Review of Financial Studies 15, 691-721.

Harris, R. G, Wiens, E, G, 1980. Government enterprise: an instrument for internal regulation of industry. Canadian Journal of Economics 13, 125-132.

Heywood, J. S., Ye, G, 2010. Optimal privatization in a mixed duopoly with consistent conjectures. Journal of Economics 101, 231-246. 
Horowitz, I., 1991. On the effects of Cournot rivalry between entrepreneurial and cooperative firms. Journal of Comparative Economics 15, 115-121.

Hsu, C. C., Lee, J. Y., Wang, L. F. S., 2018. Undesirable free entry in oligopoly with foreign competitors. In Kazuhiro Ohnishi ed., Firms' Strategic Decisions: Theoretical and Empirical Findings, Volume 3 (pp. 127-143). Bentham Science Publishers, Sharjah, UAE.

Ireland, N. J., 2003. Random pricing by labor-managed firms in markets with imperfect consumer information. Journal of Comparative Economics 31, 573-583.

Ireland, N. J., Stewart, G., 1995. On the sale of production rights and firm organization. Journal of Comparative Economics 21, 289-307.

Kim, H., 1996. Strategic excess capacity and first-mover advantage under variable demand. Seoul Journal of Economics 9, 105-122.

Laffont, J.-J., Moreaux, M., 1985. Large-market Cournot equilibria in labour-managed economies. Economia 52 153-165.

Lambertini, L., 1997. Cournot vs Stackelberg equilibria with entrepreneurial and labour managed firms. Journal of International and Cooperative Economics 5, 31-43.

Lambertini, L., 2001. Spatial competition with profit-maximising and labour-managed firms. Papers in Regional Science 80, 499-507.

Lambertini, L., Rossini, G., 1998. Capital commitment and Cournot competition with labour-managed and profit-maximising firms. Australian Economic Papers 37, 14-21.

Law, P. J., Stewart, G., 1983. Stackelberg duopoly with an Illyrian and profit-maximising firm. 
Recherches Economiques de Louvain 49, 207-212.

Lu, Y., 2007. Endogenous timing in a mixed oligopoly consisting of a single public firm and foreign competitors. Economics Bulletin 12, 1-7.

Lu, Y., Poddar, S., 2005. Mixed oligopoly and the choice of capacity. Research in Economics 59, 365-374.

Lu, Y., Poddar, S., 2009. Endogenous timing in a mixed duopoly and private duopoly 'capacity-then-quantity' game: the linear demand case. Australian Economic Papers 48, $138-150$.

Luo, J., 2013. Absorptive capacity and R\&D strategy in mixed duopoly with labor-managed and profit-maximizing firms. Economic Modelling 31, 433-439.

Matsumura, T., Kanda, O., 2005. Mixed oligopoly at free entry markets. Journal of Economics 84, $27-48$

Merrill, W., Schneider, N., 1966. Government firms in oligopoly industries: a short-run analysis. Quarterly Journal of Economics 80, 400-412.

Mujumdar, S., Pal, D., 1998. Effects of indirect taxation in a mixed oligopoly. Economics Letters $58,199-204$.

Neary, H. M., Ulph, D., 1997. Strategic investment and the co-existence of labour-managed and profit-maximising firms. Canadian Journal of Economics 30, 308-328.

Neilson, W. S., Winter, H., 1992. Unilateral most-favored-customer pricing: a comparison with Stackelberg. Economics Letters 38, 229-232. 
Nett, L., 1993. Mixed oligopoly with homogeneous goods. Annals of Public and Cooperative Economics 64, 367-393.

Nett, L., 1994. Why private firms are more innovative than public firms. European Journal of Political Economy 10, 639-653.

Novy-Marx, R., 2007. An equilibrium model of investment under uncertainty. Review of Financial Studies 20, 1461-1502.

Ohnishi, K., 2000. A two-stage price-setting equilibrium designed in consideration of goods relevance and strategic relevance. Australian Economic Papers 39, 173-183.

Ohnishi, K., 2006. A mixed duopoly with a lifetime employment contract as a strategic commitment. FinanzArchiv 62, 108-123.

Ohnishi, K., 2008. Strategic commitment and Cournot competition with labor-managed and profit-maximizing firms. Research in Economics 62, 188-196.

Ohnishi, K., 2009. Capacity investment and mixed duopoly with state-owned and labor-managed firms. Annals of Economics and Finance 10, 49-64.

Ohnishi, K., 2018. A three-stage mixed triopoly with capacity choice. In Kazuhiro Ohnishi ed., Firms' Strategic Decisions: Theoretical and Empirical Findings, Volume 3 (pp. 82-100). Bentham Science Publishers, Sharjah, UAE.

Okamura, M., Futagami, K., 1997. International competition between a profit-maximizing and labor-managed firm. Journal of International and Comparative Economics 5, 217-228.

Okuguchi, K., 1993. Cournot oligopoly with profit-maximizing and labor-managed firms. Keio 
Economic Studies 30, 27-38.

Pal, D., 1998. Endogenous timing in a mixed oligopoly. Economics Letters 61, 181-185.

Pal, D., Saha, B., 2014. Mixed duopoly and environment. Journal of Public Economic Theory 16, 96-118.

Pal, D., White, M. D., 1998. Mixed oligopoly, privatization, and strategic trade policy. Southern Economic Journal 65, 264-281.

Poddar, S., 2003. Excess capacity: a note. Keio Economic Studies 40, 75-83.

Poyago-Theotoky, J., 1998. R\&D competition in a mixed duopoly under uncertainty and easy imitation. Journal of Comparative Economics 26, 415-428.

Poyago-Theotoky, J., 2001. Mixed oligopoly, subsidization and the order of firms' moves: an irrelevance result. Economics Bulletin 12, 1-5.

Roy chowdhury, P., 2009. Mixed oligopoly with distortions: First best with budget-balance and the irrelevance principle. Economics Bulletin 29, 1885-1900.

Saha B., Sensarma, R., 2008. The distributive role of managerial incentives in a mixed duopoly. Economics Bulletin 12, 1-10.

Spence, A. M., 1977. Entry, capacity, investment and oligopolistic pricing. Bell Journal of Economics 8, 534-544.

Stephan, F. H. (Ed.), 1982. The Performance of Labour-managed Firms. Macmillan Press, London.

Stewart, G., 1991. Strategic entry interactions involving profit-maximising and labour-managed firms. Oxford Economic Papers 43, 570-583. 
Stewart, G., 1992. Management objectives and strategic interactions among capitalist and labour-managed firms. Journal of Economic Behavior and Organization 17, 423-431.

Wang, L. F. S., Wang, J., 2009. Environmental taxes in a differentiated mixed duopoly. Economic Systems 33, 389-396.

Ward, N., 1958. The firm in Illyria: market syndicalism. American Economic Review 48, 566-589.

Ware, R., 1984. Sunk costs and strategic commitment: a proposed three-stage equilibrium. Economic Journal 94, 370-378.

Ware, R., 1986. A model of public enterprise with entry. Canadian Journal Economics 19, 642-655.

Wenders, J. T., 1971. Excess capacity as a barrier to entry. Journal of Industrial Economics 20, $14-19$

White, M. D., 1996. Mixed oligopoly, privatization and subsidization. Economics Letters 53, $189-195$.

Willner, J., 1994. Welfare maximization with endogenous average costs. International Journal of Industrial Organization 12, 373-386.

Zhang, J., Li, C., 2013. Endogenous R\&D spillover and location choice in a mixed oligopoly. Annals of Regional Science 51, 459-477. 